\title{
EL REQUERIMIENTO DEL MARCO EPISTEMÓLOGICO EN LAS TESIS DE POST GRADO
}

Eulogio Hurtado-Dianderas Smith (*) E-mail: eulogio1952@hotmail.com

Félix Rivera León (**)

E-mail: felix_arl@hotmail.com

\begin{abstract}
RESUMEN
La epistemología, como teoría del conocimiento, resulta necesaria e imprescindible en la Tesis de Post Grado porque se sustenta -a su vez- en la base filosófica necesaria para la defensa del paradigma que se propone, teniendo en cuenta que los paradigmas son conjuntos de conocimientos y creencias que forman una teoría hegemónica en determinado periodo histórico.
\end{abstract}

El paradigma está constituido por supuestos teóricos, leyes y técnicas de aplicación que deberán adoptar los investigadores dentro de una comunidad científica. Por tanto, cada nuevo paradigma aporta respuestas a los enigmas que no podían resolverse con el paradigma anterior, además de otorgarle el sustento académico a toda tesis.

Por todo esto en el presente artículo se presentan las más importantes interrelaciones entre la epistemología y el método científico generalmente empleado en el desarrollo de las investigaciones en este nivel académico.

Finalmente se sostiene que en la Facultad de Ciencias Administrativas debe establecerse el requisito de que todas las tesis de Post Grado cuenten con un Marco Epistemológico.

Palabras clave: Epistemología, metodología, paradigma, marco epistemológico, tesis, investigación.

\section{ABSTRACT}

The epistemology as the theory of the knowledge is necessary and essential in the Post Degree thesis because it is sustained to a philosophical base for the defense of the proposed paradigm, considering that the paradigms are the sets of knowledge and beliefs that form a hegemonic theory in certain historical period.

The paradigms are constituted by theoretical assumptions, laws and techniques of application that will have to adopt the researchers within a scientific community. Therefore each new paradigm contributes with answers to the enigmas that could not be solved with the previous paradigm, in addition of granting the academic support to the whole thesis.

By these all, in current article it is presented the most important interrelationships between epistemology and scientific method generally employed in development of researching in this academic level.

\footnotetext{
* Doctor en Ingeniería. MBA, y Magister en Investigación y Docencia Universitaria. Docente de la Unidad de Post Grado de las Facultades de Ciencias Administrativas e Ingeniería Industrial (UNMSM).

*** Contador Público Colegiado. Profesor Asociado de la Facultad de Ciencias Administrativas (UNMSM).
} 
As a consequence, the Faculty of Administrative Sciences of this University must establish the requirement of the epistemological frame for all the Post Degree theses.

Key words: Epistemology, methodology, paradigm, epistemological frame, thesis, research.

\section{LA EPISTEMOLOGÍA Y EL MÉTODO CIENTÍFICO}

La Epistemología (del griego episteme, que significa conocimiento, logos, teoría), es la rama de la filosofía que trata de los problemas filosóficos que rodean la teoría del conocimiento. La epistemología se ocupa de la definición del saber y de los conceptos relacionados, de las fuentes, criterios, tipos de conocimiento posible y el grado con el que cada uno resulta cierto; así como la relación exacta entre el que conoce y el objeto conocido.

El método científico, según la definición de F. S. Kerlinger, se entiende como "el estudio sistemático, controlado, empírico y crítico de proposiciones hipotéticas acerca de presuntas relaciones entre varios fenómenos". El método científico es un procedimiento que aplicamos en las ciencias y se inicia con la observación.

\section{LA EPISTEMOLOGÍA Y LA METODOLOGÍA EN LA TESIS DE POSTGRADO}

Interrelaciones entre la Epistemología y el Método Científico:

- La epistemología es la investigación sobre la naturaleza de la práctica científica.

- El método científico es el proceso mediante el cual una teoría científica es validada o bien descartada.

- La epistemología estudia a la investigación científica y al producto que se obtiene de esta investigación.

- El método científico es el modo ordenado de proceder para el conocimiento de la verdad, en el ámbito de determinada disciplina científica.

- La epistemología es una rama de la filosofía mientras que el método científico es un procedimiento que seguimos aplicado a la ciencia.

- La epistemología se ocupa de todos los elementos que procuran la adquisición de cono- cimiento e investiga los fundamentos, límites, métodos y validez del mismo.

- El método científico se ocupa del conjunto de estrategias que usan los científicos para desarrollar su función, es decir, hacer ciencia.

- La epistemología es aquella parte de la ciencia que tiene como objeto (no el único) hacer un recorrido por la historia del sujeto respecto a la construcción del conocimiento científico; es decir, la forma cómo éste ha objetivado, especializado y otorgado un estatus de cientificidad al mismo; pero a su vez, el reconocimiento que goza este tipo de conocimiento por parte de la comunidad científica.

- La epistemología busca explicar la naturaleza y la obtención de las teorías y conceptos científicos.

- La epistemología trata sobre como la ciencia explica, predice y controla la naturaleza.

- La epistemología debe explicar los medios para determinar la validez de la información.

- La epistemología define si es correcta la formulación y el uso del método científico.

- La epistemología desarrollan los tipos de razonamiento utilizados para llegar a las conclusiones

\section{Cuadro 1}

Interrelación entre Epistemología y el Método Científico.

\begin{tabular}{|l|l|}
\hline Método científico & Epistemología \\
\hline $\begin{array}{l}\text { Estudia el método } \\
\text { científico }\end{array}$ & $\begin{array}{l}\text { Estudia el } \\
\text { conocimiento } \\
\text { científico }\end{array}$ \\
\hline Analiza un método & Analiza un concepto \\
\hline $\begin{array}{l}\text { Construye } \\
\text { métodos } \\
\text { cientificos }\end{array}$ & $\begin{array}{l}\text { Construye } \\
\text { términos } \\
\text { teóricos }\end{array}$ \\
\hline $\begin{array}{l}\text { Cuando tienen } \\
\text { alguna limitación } \\
\text { pueden dar origen } \\
\text { a una crisis }\end{array}$ & $\begin{array}{l}\text { La crisis hace } \\
\text { renacer la } \\
\text { epistemolgía }\end{array}$ \\
\hline \multicolumn{2}{|c|}{ Hoy en día es muy difícil } \\
desligar uno del otro
\end{tabular}


- La epistemología es capaz de revelar las implicaciones de los diferentes métodos y modelos de la ciencia.

- El método científico implica una combinación de inducción y deducción que se retroalimentan.

- El método científico se fundamenta en la reproducibilidad y la falsabilidad.

- El método científico se puede sintetizar en los siguientes pasos: observación, descripción, inducción, hipótesis, experimentación, verificación, y replicación. La epistemología no es una secuencia de pasos.

- La epistemología es una ciencia que puede producir conclusiones sobre nuestras observaciones del mundo real.

\section{CONCLUSIÓN}

Ante todas las evidencias arriba mencionadas se puede deducir la necesidad de establecer como requisito necesario e indispensable que en las tesis de Post Grado que se presenten en la Unidad de Post Grado de la Facultad de Ciencias Administrativas, presenten el Marco Epistemológico que brinde una mayor consistencia académica y científica al paradigma que contiene o deben contener los trabajos de investigación, que finalmente van a explicitar el o los aportes a las ciencias administrativas.

\section{BIBLIOGRAFIA}

Icart Isern, Teresa y otras. Elaboración y presentación de un proyecto de investigación de una tesina.

Kerlinger, Fred (1986). Investigación de Comportamientos. México, Ed. Mc Graw-Hill.

Kuhn, T. (1971). La Estructura de las Revoluciones Científicas.

Kuhn, T. (1975). La Estructura de las Revoluciones Científicas.

Luna Castillo, Antonio (2000). Metodología de la tesis. Ed. Trillas.

Mendez Ramírez, J. (2000). Protocolo de la investigación. Ed. Trillas.

Polit-Hungler. (1986). Investigación Científica en las Ciencias de la Salud. México, Ed. Mc Graw-Hill.

Ramírez, Tulio (2002). Cómo hacer un Proyecto de Investigación. Venezuela, Ed. Panapo.

Rosado, Miguel Ángel (2003). Metodología de la Investigación y Evaluación. Ed. Trillas.

Sonja, Juan (2001). Epistemología y metodología. Quinta Edición. Buenos Aires.

Tamayo y Tamayo, Mario (2003). El Proceso de la Investigación Científica. México, Ed. LIMUSA. 